TITLE:

\title{
Micro-feeding of fine powders using a capillary tube with ultrasonic vibration
}

\section{AUTHOR(S):}

Matsusaka, Shuji; Urakawa, Motohiro; Masuda, Hiroaki

\section{CITATION:}

Matsusaka, Shuji ...[et al]. Micro-feeding of fine powders using a capillary tube with ultrasonic vibration. Advanced Powder Technology 1995, 6(4): 283-293

\section{ISSUE DATE:}

1995

URL:

http://hdl.handle.net/2433/217931

\section{RIGHT:}

(C) 1995. This manuscript version is made available under the CC-BY-NC-ND 4.0 license http://creativecommons.org/licenses/by-nc-nd/4.0/; この論文は出版社版でありません。 引用の際には出版社版をご確認ご利用ください。; This is not the published version.

Please cite only the published version. 
Micro-feeding of fine powders using a capillary tube with ultrasonic vibration

\author{
SHUJI MATSUSAKA, MOTOHIRO URAKAWA and HIROAKI MASUDA
}

Department of Chemical Engineering, Kyoto University Yoshida-honmachi, Sakyo-ku, Kyoto 606-01, Japan

\begin{abstract}
Micro-feeding of fine powders has been studied experimentally by use of a vibrating capillary tube whose diameter is varied from 0.58 to $1.26 \mathrm{~mm}$. Ultrasonic vibration of $20 \mathrm{kHz}$ was generated by a piezoelectric transducer and applied to the tube so as to discharge micron or sub-micron particles. The mechanism of the powder flow in the vibrating capillary tube is deduced, such that a thin layer of particles near the inner wall acts as a lubricant through their micro-vibrations. Therefore, the inner powder easily passes through the tube by the force of gravity. The powder flow rate, velocity and packing fraction of particles in the capillary tube were also obtained. Furthermore, a new factor corresponding to the viscosity of fluid was introduced in characterizing the powder discharge. From the experiments using various fine powders, it was found that the continuous operation of micro-feeding was possible even at a rate of milligrams per second.
\end{abstract}




\section{NOMENCLATURE}

a amplitude of vibration [m]

$D_{\text {ag50 }}$ mass median diameter of agglomerated particle [m]

$D_{\mathrm{p} 50} \quad$ mass median diameter of primary particle [m]

$d \quad$ inner diameter of a capillary tube [m]

$f \quad$ frequency of vibration $[\mathrm{Hz}]$

$g \quad$ gravitational acceleration $\left[\mathrm{m} / \mathrm{s}^{2}\right]$

$k \quad$ constant in Eq. (7) [m/s]

$L \quad$ length of a capillary tube [m]

$l \quad$ effective thickness of a thin layer of micro-vibrating particles [m]

$P \quad$ electric power of ultrasonic vibration [W]

$S \quad$ area of a particle layer $\left[\mathrm{m}^{2}\right]$

$t$ time [s]

$v \quad$ velocity of powder $[\mathrm{m} / \mathrm{s}]$

$W \quad$ powder flow rate $[\mathrm{kg} / \mathrm{s}]$

$\mu \quad$ factor defined by Eq. (2) [Pa·s]

$\rho_{\mathrm{p}} \quad$ particle density $\left[\mathrm{kg} / \mathrm{m}^{3}\right]$

$\tau \quad$ wall frictional stress $[\mathrm{Pa}]$

$\phi \quad$ packing fraction [-] 


\section{INTRODUCTION}

The performance of composite products such as ceramic sensors, toners, etc., which are made from various fine powders is influenced by the composition. In order to keep the high quality of these composite products, mass control of raw materials is important; hence, a micro-feeding system of fine powders is required in industrial processes as well as in research and development.

In general, large particles have high flowability and feeding them is rather easy. Smaller particles, however, agglomerate readily and consequently feeding becomes difficult [1]. For micro-feeding of these small particles, the agglomerated particles should be disintegrated as small as possible using effective and continuous external forces with a simple mechanism $[2,3]$. As a result of these requirements, a new method using a vibrating capillary tube (inner diameter: $d=0.4 \sim 1.6 \mathrm{~mm}$, frequency: $f \leq 760 \mathrm{~Hz}$ ) was developed [4]. Fine particles (about $10 \mu \mathrm{m}$ in size) were continuously discharged even at a rate of $0.2 \mathrm{mg} / \mathrm{s}$. Furthermore, the capillary tube can be applied to feed fine particles into a limited area. The critical condition in attaining a successful powder discharge was related to vibrational acceleration $\left(=a(2 \pi f)^{2}\right)$. The fact shows that a high frequency will be effective in discharging more adhesive smaller particles. Therefore, we paid attention to applying ultrasonic vibration. Although Saito et al. applied ultrasonic vibration to the powder feeding [3], the size of the particles used and the feeding rate are relatively large compared with our purpose.

Our study here is to develop a micro-feeding system, which is applicable to fine powders as small as $0.4 \mu \mathrm{m}$ even at a feeding rate of milligrams per second.

\section{EXPERIMENTAL APPARATUS AND PROCEDURE}

Figure 1 shows the experimental apparatus for micro-feeding. A fine powder was filled in a hopper and discharged from a capillary tube whose diameter was varied between 0.58 and $1.26 \mathrm{~mm}$. A piezoelectric transducer of $20 \mathrm{kHz}$ (Ohtake works Co. Sonicator ${ }^{\circledR}$ ) was used so as to generate ultrasonic vibration. Electric power was controlled in a range of $50 \sim 160 \mathrm{~W}$. A combination of an exponential horn and a straight horn (diameter: $20 \mathrm{~mm}$ ) was attached as shown in Fig. 1. The medium of propagation of the ultrasonic vibration was water in a bath of $90 \mathrm{~mm}$ diameter and $200 \mathrm{~mm}$ height. The mass of powder discharged from the capillary tube was continuously measured by an electric balance with a resolution of $0.1 \mathrm{mg}$ and the data were sampled into a computer. A video-microscope was used to obtain information for the 


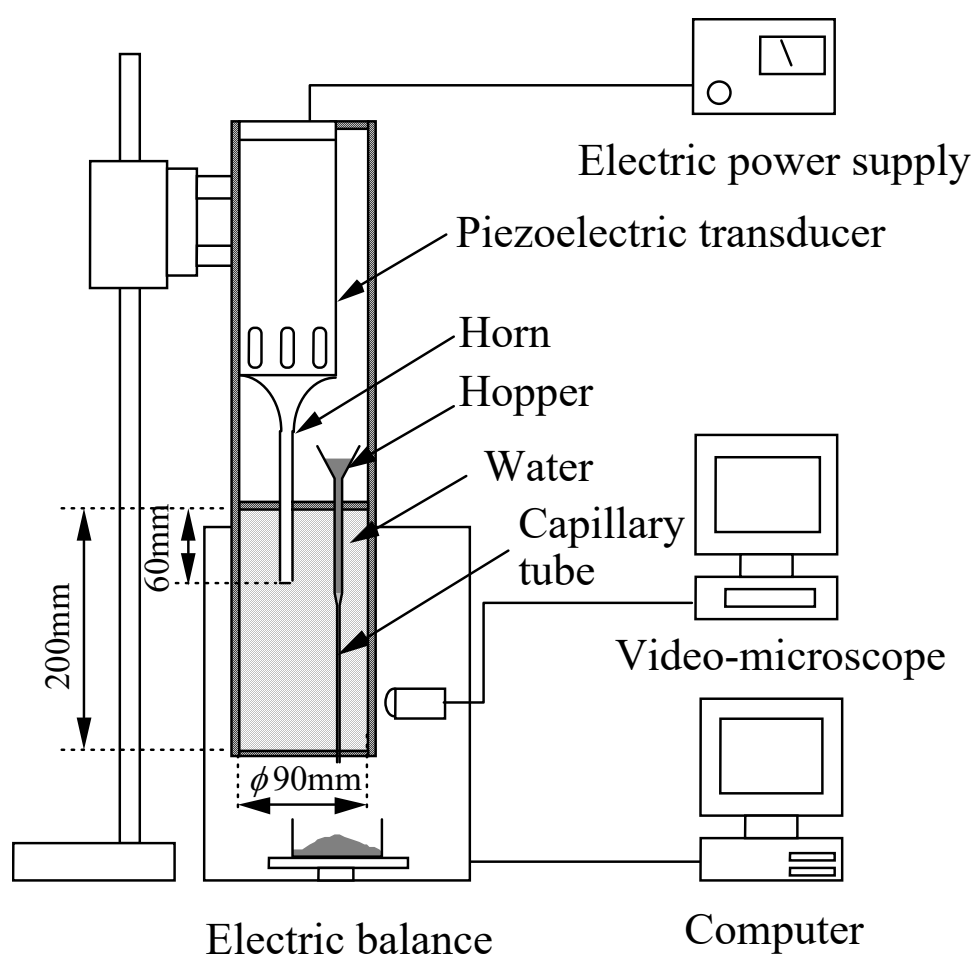

Figure 1. Experimental apparatus.

Table 1.

Test powders used

\begin{tabular}{lcc}
\hline Material & $D_{\mathrm{p} 50}(\mu \mathrm{m})$ & $\rho_{\mathrm{p}} \times 10^{-3}\left(\mathrm{~kg} / \mathrm{m}^{3}\right)$ \\
\hline Fly-ash & 5 & 2.2 \\
& 15 & 2.2 \\
Alumina & 1 & 4.0 \\
& 3 & 4.0 \\
& 5 & 4.0 \\
& 8 & 4.0 \\
& 10 & 4.0 \\
& 16 & 4.0 \\
Alumina (spherical) & 20 & 4.0 \\
& 40 & 4.0 \\
Antimony trioxide & 10 & 4.0 \\
Silicon carbide & 4 & 4.0 \\
Kanto roam & 7 & 5.2 \\
Calcium bicarbonate & 0.4 & 5.2 \\
& 2 & 3.1 \\
& 2 & 3.0 \\
\end{tabular}

measurement of powder velocity in the tube. The test powders used are shown in Table 1 . The experiments were conducted under room conditions (temperature: $18 \sim 24^{\circ} \mathrm{C}$ and relative humidity: $55 \sim 75 \%$ ). 


\section{RESULTS AND DISCUSSION}

\subsection{Powder discharge from a capillary tube}

In general, fine powder cannot pass through a capillary tube because of adhesion to the inner wall. However, ultrasonic vibration enables fine powder to pass through it. Figure 2 shows a photograph taken while powder was dropping from a capillary tube. The tube was full of powder and the powder movement was approximated by a plug flow. From the end of the capillary tube, a small lump of powder was dropping at a certain time interval. The mass of each lump was about $0.4 \mathrm{mg}$ under these conditions.

\subsection{Mechanism of powder flow in a capillary tube}

In order to clarify the mechanism of the powder flow in the vibrating capillary tube, we carried out an experiment on the behavior of particles on a vibrating surface of a flat plate (JIS SUS304, $90 \mathrm{~mm}$ diameter and $0.5 \mathrm{~mm}$ thick). A cylindrically shaped powder bed was formed with a diameter of $3 \mathrm{~mm}$ and a height of 0.3 or $1.5 \mathrm{~mm}$, and it was placed on the center of the

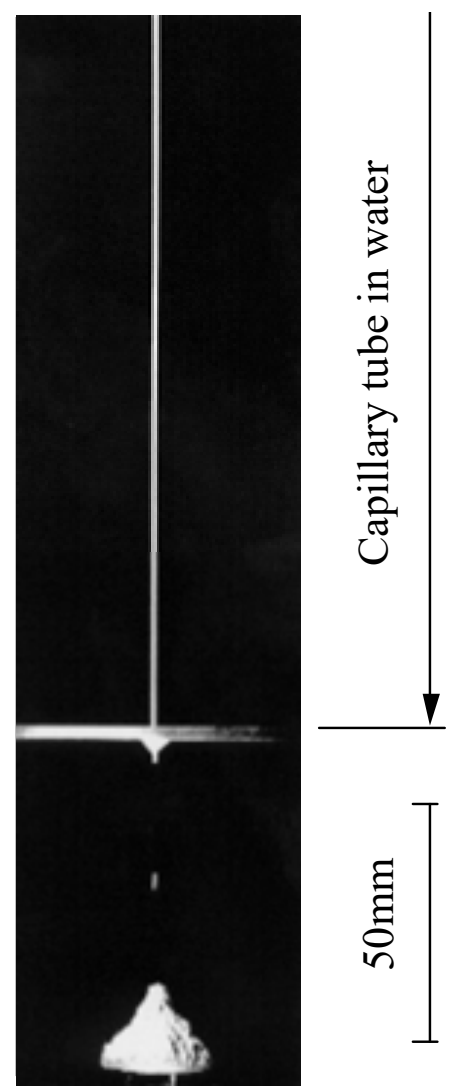

Figure 2. Powder discharge from a capillary tube (fly-ash, $D_{\mathrm{p} 50}=15 \mu \mathrm{m}, d=0.69 \mathrm{~mm}$, $L=140 \mathrm{~mm}, P=100 \mathrm{~W}$, an exposure of $1 / 250 \mathrm{~s}$ ). 

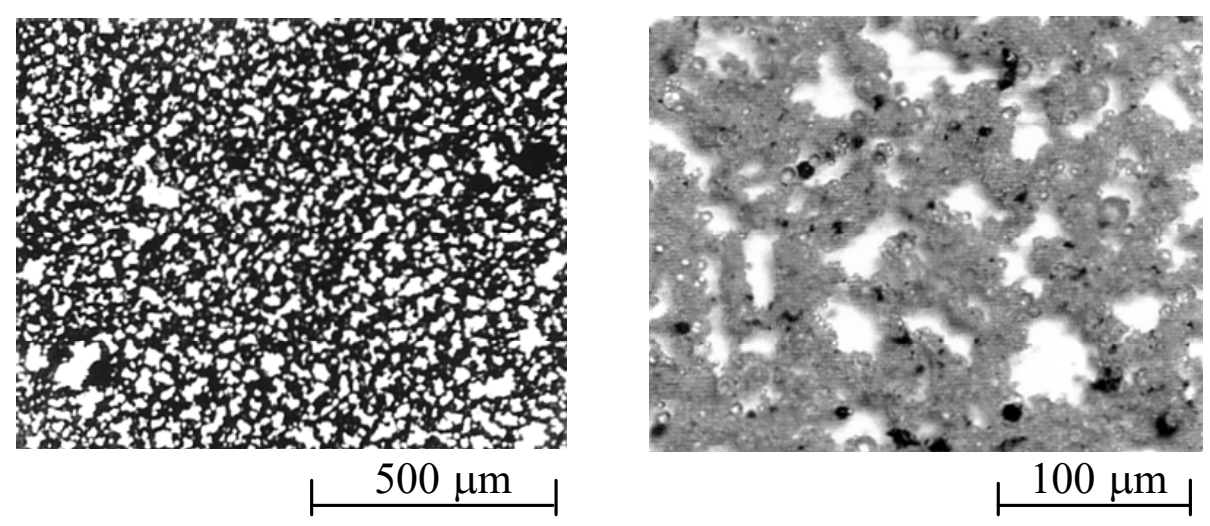

Figure 3. Particles on a vibrating surface after $30 \mathrm{~min}$ of operation (fly-ash, $D_{\mathrm{p} 50}=5 \mu \mathrm{m}, P=100 \mathrm{~W}$ ).

plate which was set on water. When the ultrasonic vibration started, the powder was immediately disintegrated and spread over the surface. As a typical example, photomicrographs of the particles on the vibrating surface after $30 \mathrm{~min}$ of operation are shown in Fig. 3. Small agglomerated particles are dispersed uniformly and a mono-layer of the agglomerated particles is formed.

Microscopic observation showed that the particles were moving randomly at high frequency on the surface. The particles collide with each other and form agglomerates; however, larger agglomerates are disintegrated because of collision with other particles or with the plate surface. Namely, the size of agglomerated particles is controlled by a balance of agglomeration and disintegration.

Figure 4 shows the area occupied by the particle layer on the vibrating surface as a function of time elapsed. The area immediately increases and reaches to a certain limiting value. Comparing Fig. 4(a) and (b), there is no difference in the tendency of the area to increase irrespective of the initial height of the powder bed $(0.3$ or $1.5 \mathrm{~mm})$.

The final heights of the particle layers, i.e. the diameters of the agglomerated particles on the vibrating surface, were measured with various powders and shown in Fig. 5 with dimensionless diameter $D_{\mathrm{ag} 50} / D_{\mathrm{p} 50}$. They decrease with an increase in the primary particle diameter $D_{\mathrm{p} 50}$. Agglomerates are not formed for particles whose mass median diameter is larger than about $20 \mu \mathrm{m}$. The solid line in Fig. 5 indicates $D_{\mathrm{ag} 50}=20 \mu \mathrm{m}$, showing all powders form agglomerates of $20 \mu \mathrm{m}$. 

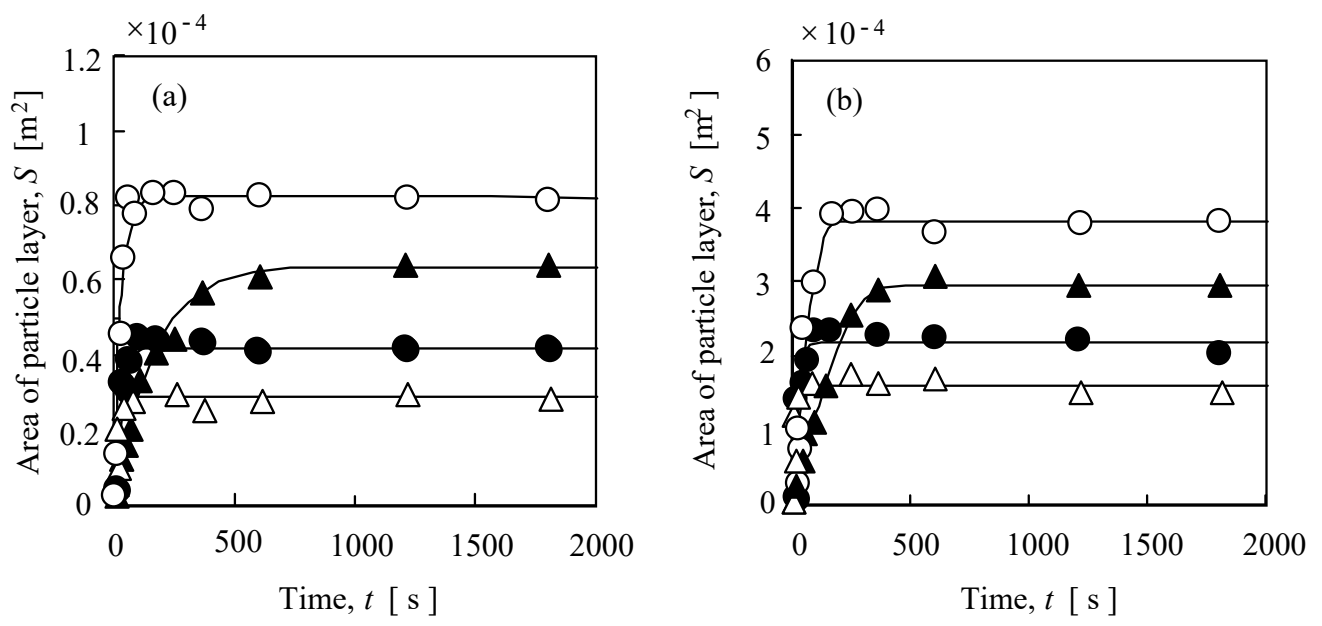

Figure 4. Area occupied by the particle layer on a vibrating surface as a function of time elapsed $(P=100 \mathrm{~W})$. (a) Initial height of powder $0.3 \mathrm{~mm}$, (b) $1.5 \mathrm{~mm}$ (०: spherical alumina, $D_{\mathrm{p} 50}=3 \mu \mathrm{m} ; \boldsymbol{\Delta}$ : alumina, $D_{\mathrm{p} 50}=5 \mu \mathrm{m} ; \bullet \bullet$ fly-ash, $D_{\mathrm{p} 50}$ $=15 \mu \mathrm{m} ; \Delta$ : alumina, $\left.D_{\mathrm{p} 50}=16 \mu \mathrm{m}\right)$.

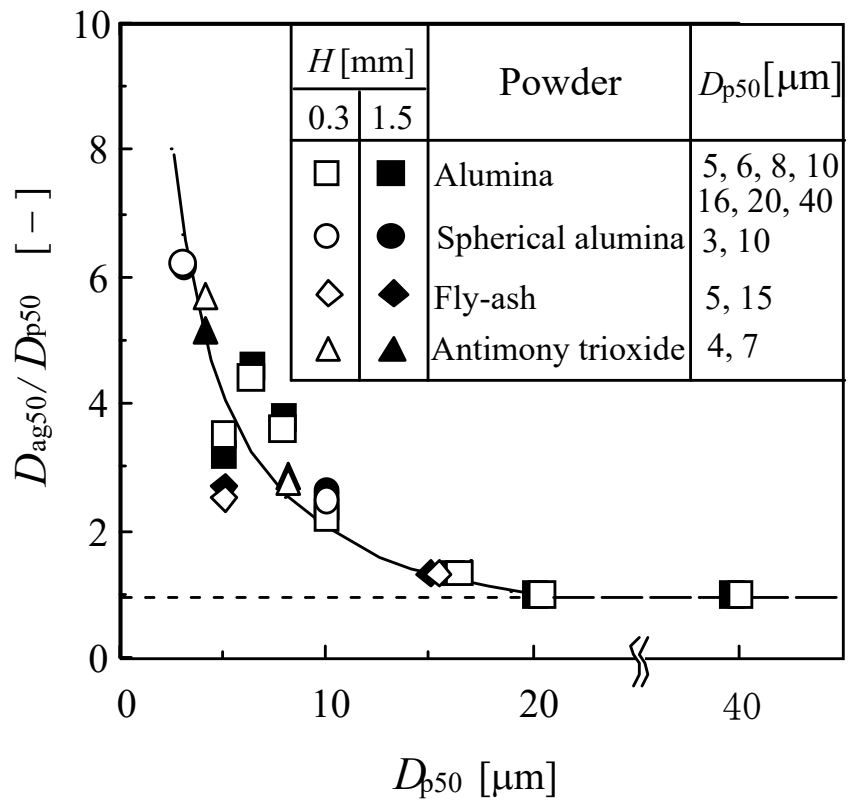

Figure 5. Dimensionless diameter of agglomerated particle $D_{\text {ag50 }} / D_{\mathrm{p} 50}$ as a function of primary particle size $(P=100 \mathrm{~W})$.

When the vibrating flat surface was tilted slightly ( $3^{\circ}$ from the horizontal line), all the agglomerated particles on the surface moved slowly downward by gravity, showing that the adhesion between the agglomerated particles and the vibrating surface was quite weak. 
On the basis of the above observation, the mechanism of powder flow in the vibrating capillary tube is considered as follows. There is a thin layer of micro-vibrating particles between the wall and the inner powder plug, and the layer acts as a lubricant. As a result, the inner powder passes through the capillary tube by gravity even if the inner powder does not have sufficient flowability. The powder movement is approximated by a plug flow. Therefore, the powder flow rate can be represented by the following equation, neglecting the wall layer thickness:

$$
W=\rho_{\mathrm{p}} v \phi \frac{\pi d^{2}}{4}
$$

where $\rho_{\mathrm{p}}$ is the particle density, $v$ is the velocity and $\phi$ is the packing fraction.

\subsection{Powder flow rate, velocity and packing fraction}

Figure 6 shows the powder flow rate of fly-ash as a function of (a) the inner diameter of a capillary tube or (b) the electric power of ultrasonic vibration. Micro-feeding as low as 40 $\mu \mathrm{g} / \mathrm{s}$ was attained in this experiment. The powder flow rate $W$ increases monotonously with the tube diameter $d$ and also increases with the electric power $P$ as long as the tube diameter is
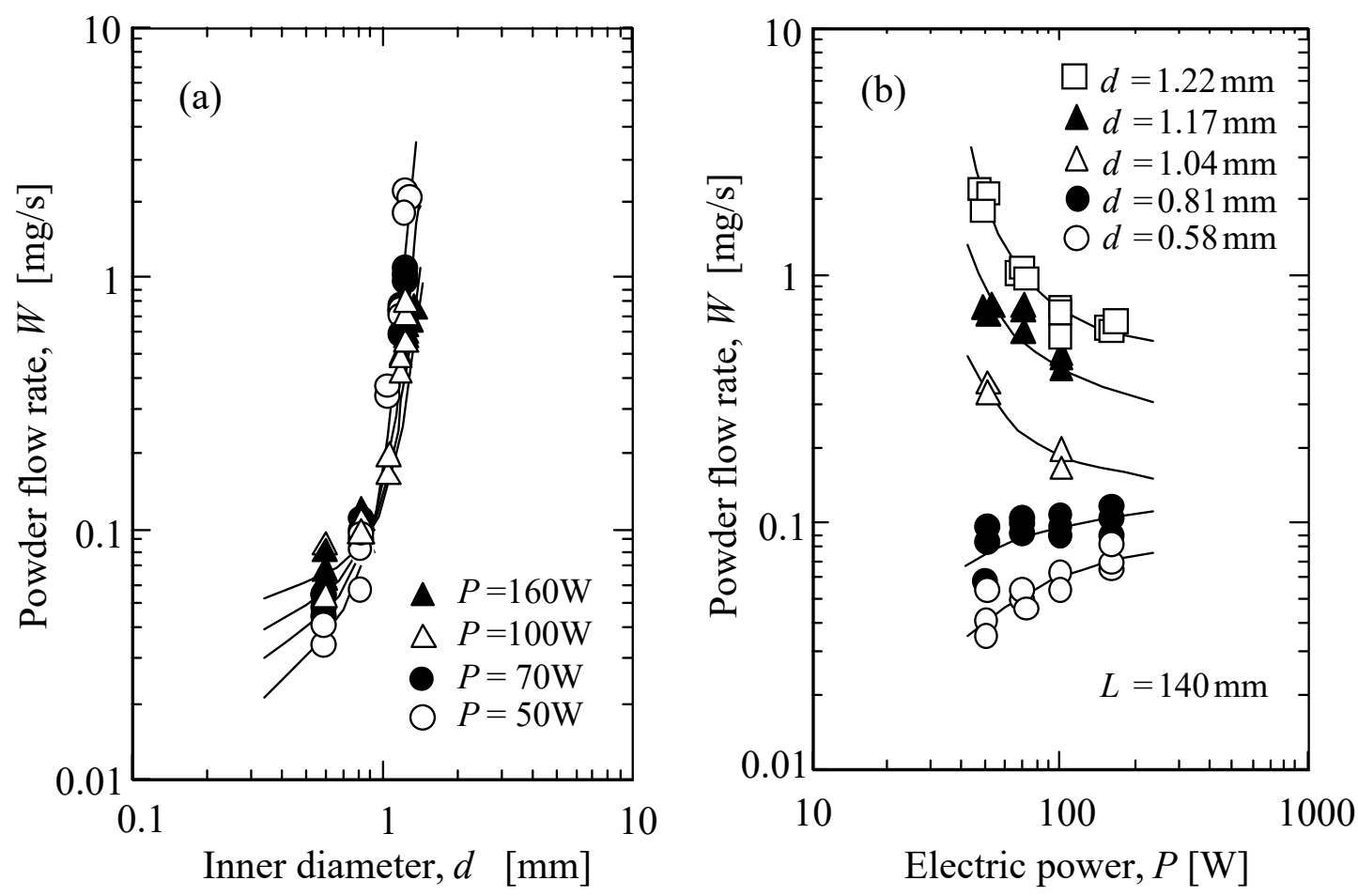

Figure 6. Powder flow rate $W$. (a) Effect of inner diameter $d$. (b) Effect of electric power $P$. Fly-ash: $D_{\mathrm{p} 50}=15 \mu \mathrm{m}$. 

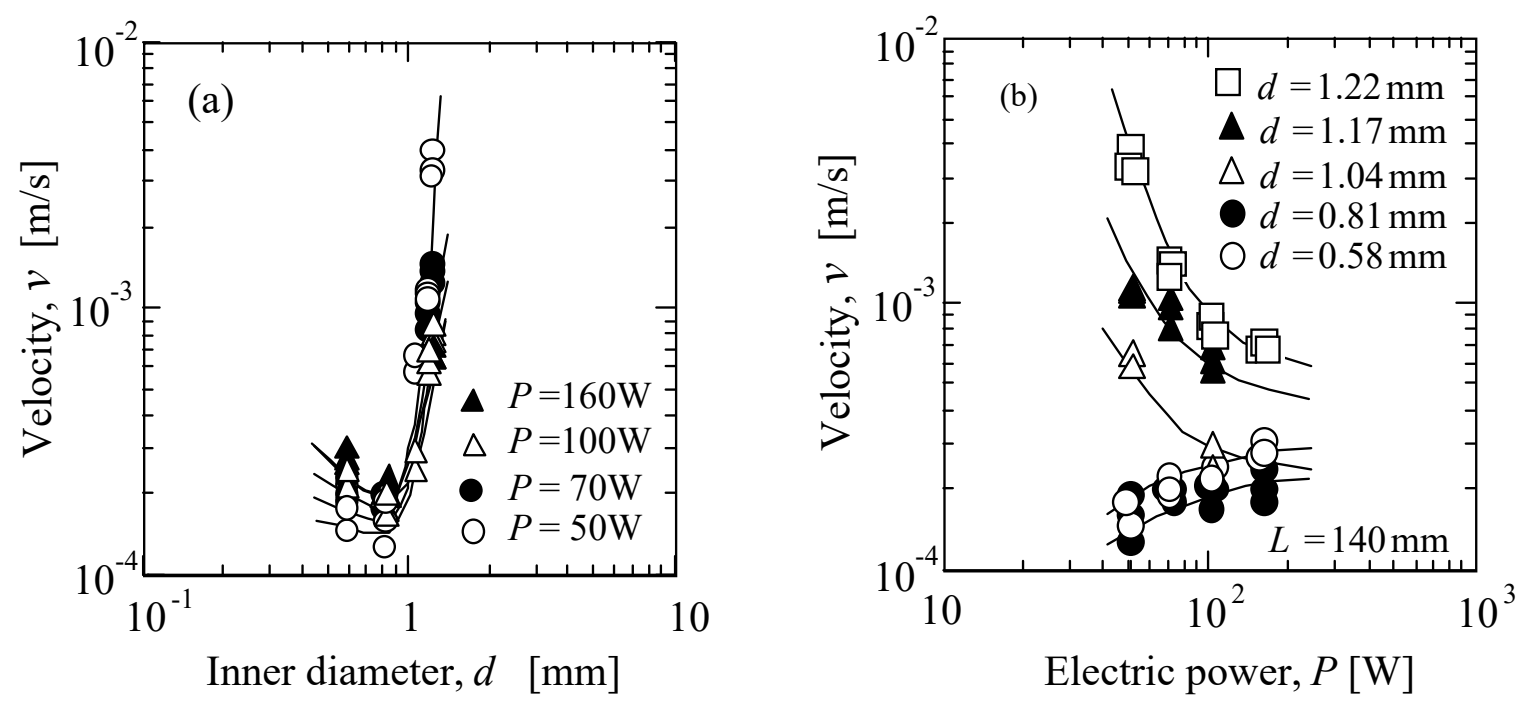

Figure 7. Powder velocity through a capillary tube. (a) Effect of inner diameter $d$.

(b) Effect of electric power $P$. Fly-ash: $D_{\mathrm{p} 50}=15 \mu \mathrm{m}$.
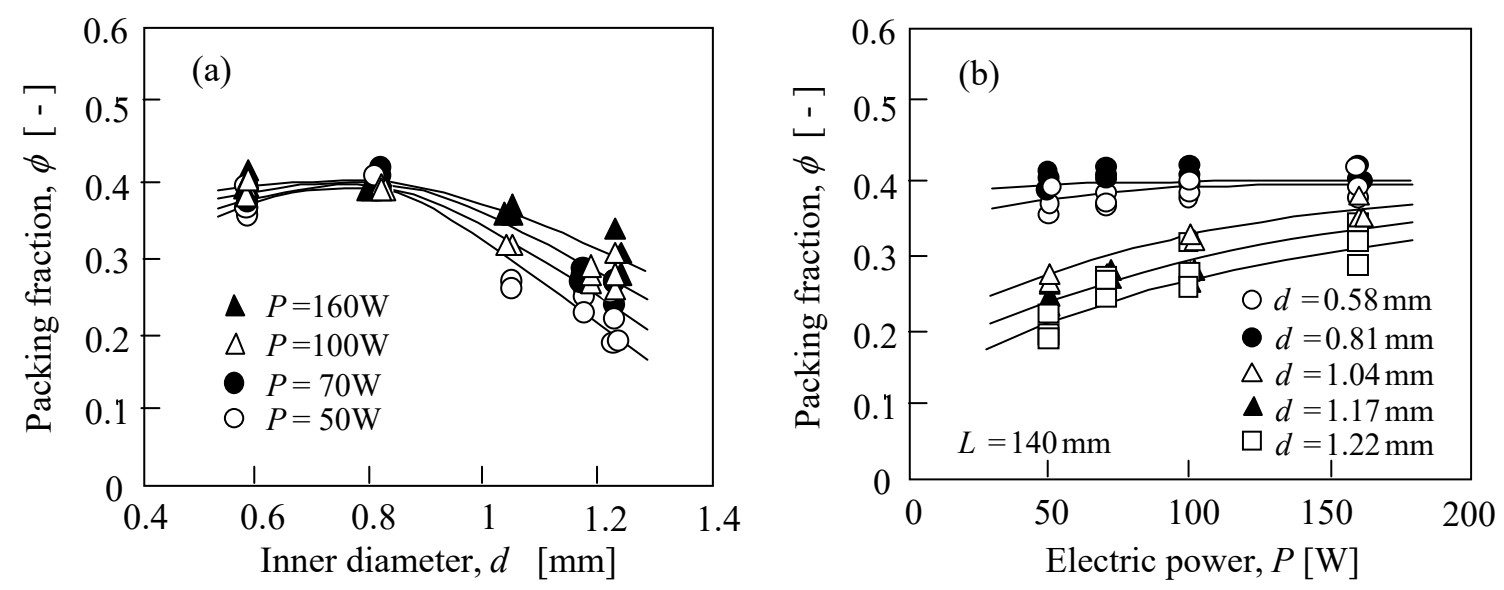

Figure 8. Packing fraction in a capillary tube. (a) Effect of inner diameter $d$.

(b) Effect of electric power $P$. Fly-ash: $D_{\mathrm{p} 50}=15 \mu \mathrm{m}$.

$0.81 \mathrm{~mm}$ or less, while it decreases when the diameter is $1.04 \mathrm{~mm}$ or more.

Powder velocity in the capillary tube is shown in Fig. 7 as a function of the inner diameter or the electric power. Although the velocity was very slow, the powder flow was stable. The velocity slightly decreases with an increase in the diameter below $0.8 \mathrm{~mm}$, but increases above $0.8 \mathrm{~mm}$. Figure 7(b) shows that the velocity $v$ increases with the electric power when the tube diameter is $0.81 \mathrm{~mm}$ or less, but decreases when it is $1.04 \mathrm{~mm}$ or more. It is interesting that there are two different tendencies in the velocity variations. This is probably caused by the variation of the packing fraction. 
Since the packing fraction could not be measured directly, it was calculated by use of Eq. (1) with experimental data of the powder flow rate and the velocity. The results are shown in Fig. 8. The packing fraction slightly increases with the tube diameter below $0.8 \mathrm{~mm}$, but decreases above $0.8 \mathrm{~mm}$. Figure $8(\mathrm{~b})$ shows that the packing fraction increases with the electric power, in particular it greatly varies when the diameter is $1.04 \mathrm{~mm}$ or more.

These results show that vibration has two roles: raising flowability and raising packing fraction. When the packing fraction increases, the flowability decreases. Namely, whether the powder flow rate increases with the power of the vibration or not is dependent on the variation of these two factors.

\subsection{Characterization of the powder discharge}

As mentioned in section 3.2, a thin layer of micro-vibrating particles near the wall is very important for the powder discharge. It is similar to the boundary layer of fluid flow. Now, we introduce a new factor $\mu$ as follows:

$$
\mu=\frac{\tau l}{v}
$$

where $\tau$ is the wall frictional stress, $l$ is the effective thickness of the thin layer and $v$ is the velocity of powder. The factor $\mu$ corresponds to the viscosity of Newtonian fluid. If the force of gravity exerted on the powder in a capillary tube is equal to the frictional force on the wall, the force balance per unit length gives the following equation:

$$
\frac{\pi d^{2}}{4} \rho_{\mathrm{p}} \phi g=\pi d \tau
$$

where $g$ is the gravitational acceleration. Equation (3) is rewritten as follows:

$$
\tau=\frac{\rho_{\mathrm{p}} \phi d g}{4}
$$

From Eqs (2) and (4), the following equation is derived:

$$
\mu=\frac{\rho_{\mathrm{p}} \phi d l g}{4 v}
$$

Figure 9 shows the relationship between the factor $\mu$ and the packing fraction $\phi$. The value of $\mu$ increases with the packing fraction, and $\mu$ is experimentally represented as a function of $\phi$ irrespective of the inner diameter of the tube and the electric power of the vibration:

$$
\mu=8 \phi^{4}
$$

From Eqs (5) and (6), the following relation is obtained between the velocity $v$ and the packing fraction $\phi$ : 


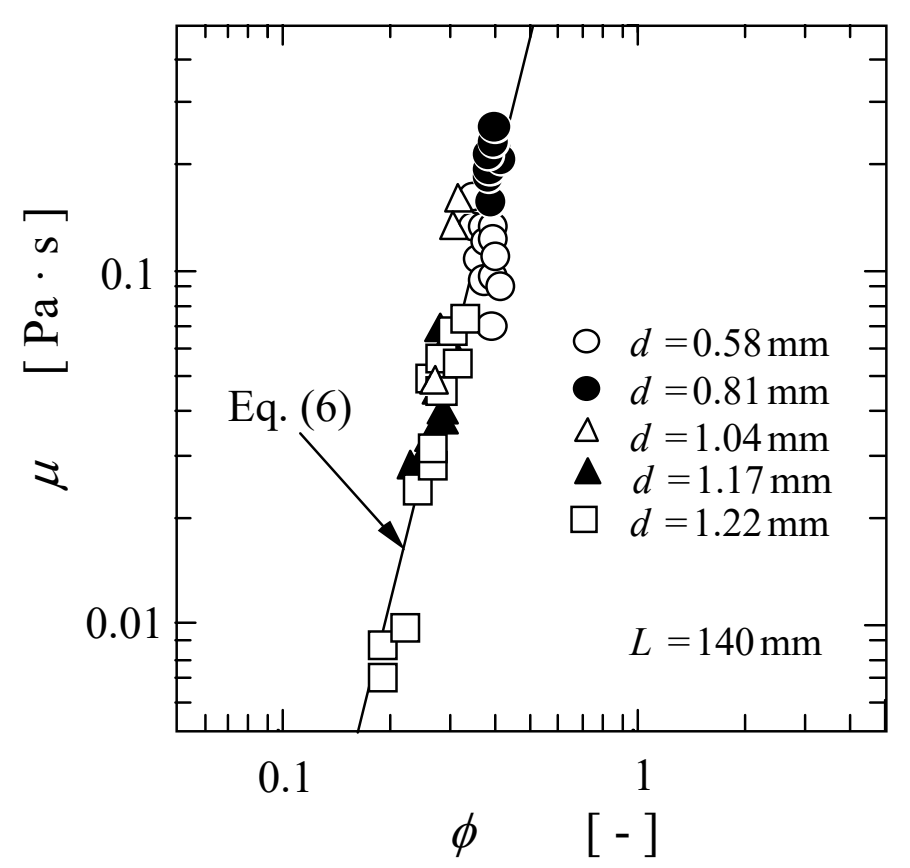

Figure 9. Relationship between factor $\mu$ and packing fraction $\phi$ $(P=50 \sim 160 \mathrm{~W}, l=20 \mu \mathrm{m}$ in Eq. 5).

$v=\frac{k}{\phi^{3}}$

where

$$
k=\frac{\rho_{\mathrm{p}} d l g}{32}, \quad l \approx 20 \mu \mathrm{m}
$$

\subsection{Discharge of various fine powders}

The powder flow rates for various fine powders are shown in Fig. 10 as a function of time elapsed. In these experiments, a capillary tube with an inner diameter of $1.26 \mathrm{~mm}$ and a length of $50 \mathrm{~mm}$ was used. The tip of the ultrasonic horn was placed about $1 \mathrm{~mm}$ away from the capillary tube and the electric power applied was $100 \mathrm{~W}$. A series of six measurements, (each measurement time $=10 \mathrm{~s}$ ) was carried out every $900 \mathrm{~s}$. The powder flow rate was rather high in the early stage. This is because it takes a period of time until the packing fraction in the capillary tube reaches the steady-state value. The temperature of the water was raised up to about $40^{\circ} \mathrm{C}$ by the ultrasonic vibration. However, there was no effect on the powder flow rate. Furthermore, there was no problem even using hot water at $60^{\circ} \mathrm{C}$. These results show that continuous operation of the micro-feeding system is possible. 


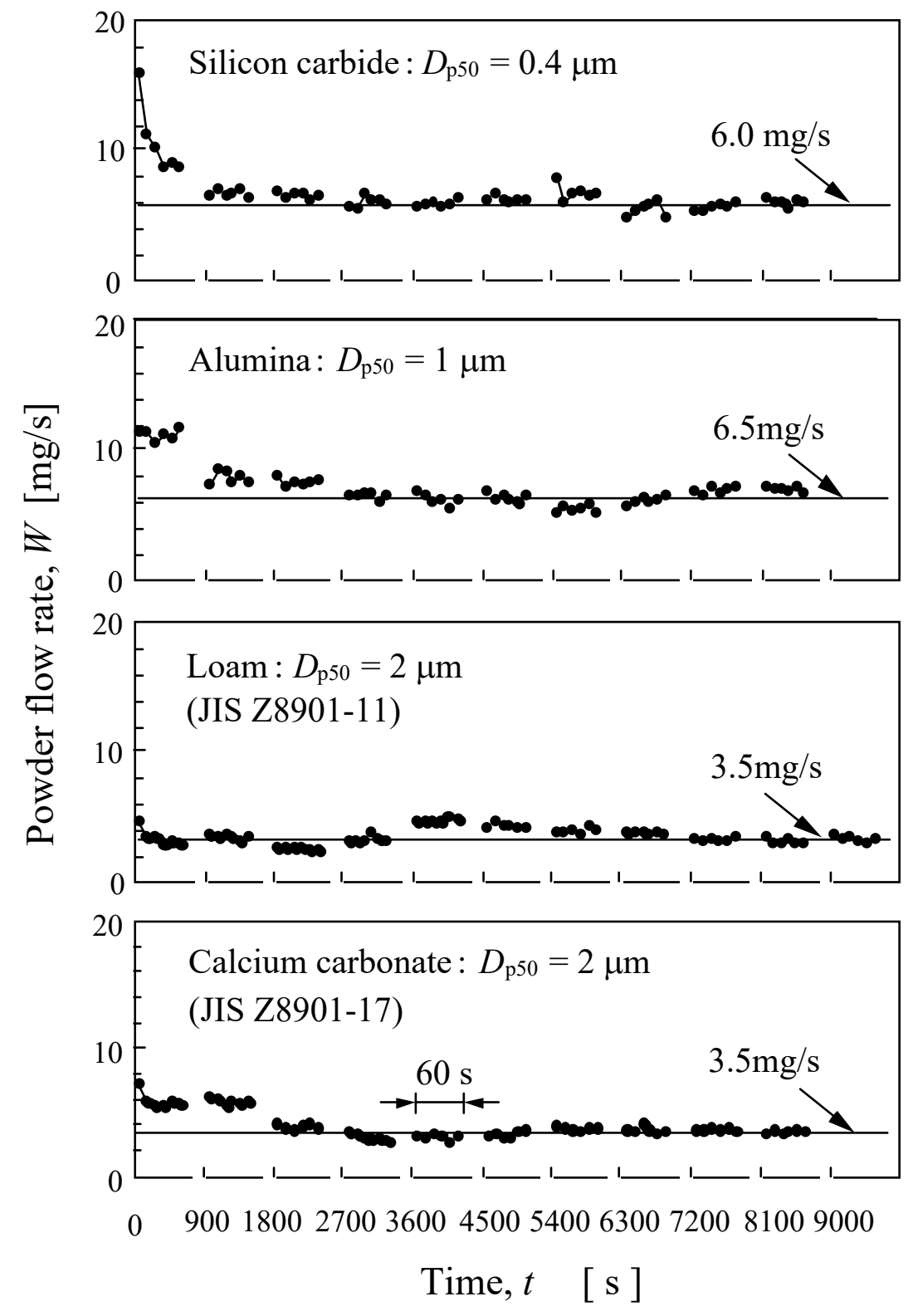

Figure 10. Discharge of various fine powders $(d=1.26 \mathrm{~mm}, L=50 \mathrm{~mm}, P=100 \mathrm{~W})$

\section{CONCLUSION}

The following conclusions can be drawn by the powder feeding experiments using ultrasonic vibration.

(1) A fine powder placed on a plate was immediately disintegrated and spread over the surface when an ultrasonic vibration was applied to the bottom side of the plate. The particles moved randomly at high frequency on the surface and a mono-layer of agglomerated particles $(\approx 20 \mu \mathrm{m})$ was formed. 
(2) Fine powder passed through a vibrating capillary tube and the powder movement was approximated by a plug flow with a thin boundary layer near the inner wall. The layer made up of micro-vibrating particles acts as a lubricant for the powder flow.

(3) The powder discharge was characterized by a new factor that corresponds to the viscosity of Newtonian fluid. The factor was proportional to the fourth power of the packing fraction irrespective of the inner diameter and the electric power of ultrasonic vibration.

(4) The continuous operation of micro-feeding of micron or sub-micron particles was possible even at a rate of milligrams per second.

\section{Acknowledgement}

This research was supported by a Grant-in-Aid for Encouragement of Young Scientists no. 07855086 from the Ministry of Education, Science and Culture, Japan.

\section{REFERENCES}

1. H. Masuda, H. Kurahashi, M. Hirota and K. Iinoya, Micro-feeding by table feeder. Kagaku Kogaku Ronbunshu. 2, 286-290, 1976.

2. H. Seno and T. Kondo, Development of the micro-feeder for fine particles. J. Soc. Powder Technol., Japan, 26, 340-344, 1989.

3. M. Saito, O. Kimura and N. Yoda, A quantitative powder supply method using ultrasonic vibration. J. Acoustical Soc., Japan, 45, 38-43, 1989.

4. S. Matsusaka, K. Yamamoto and H. Masuda, Micro-feeding of a fine powder using a vibrating capillary tube. J. Soc. Powder Technol., Japan, 32, 83-88, 1995. 